\title{
Comparison of novel and existing tools for studying drug sensitivity against the hookworm Ancylostoma ceylanicum in vitro
}

\author{
LUCIENNE TRITTEN ${ }^{1,2}$, OLIVIER BRAISSANT ${ }^{3}$ and JENNIFER KEISER ${ }^{1,2} *$ \\ ${ }^{1}$ Department of Medical Parasitology and Infection Biology, Swiss Tropical and Public Health Institute, \\ P.O. Box, CH-4002 Basel, Switzerland \\ ${ }^{2}$ University of Basel, P.O. Box, CH-4003 Basel, Switzerland \\ ${ }^{3}$ Laboratory of Biomechanics and Biocalorimetry, Biozentrum/Pharmazentrum, University of Basel, Switzerland
}

(Received 7 August 2011; revised 30 September and 18 November 2011; accepted 23 November 2011)

S U M MARY

The motility assay is the current gold standard for evaluating drug effects on hookworm larvae and adults, however, among other drawbacks the assay is time consuming, and prone to individual subjectivity. We evaluated six alternative in vitro assays, namely the feeding inhibition assay, the colourimetric AlamarBlue ${ }^{\circledR}$, MTT formazan and acid phosphatase activity assays, as well as isothermal calorimetry and the xCELLigence System using Ancylostoma ceylanicum third-stage larvae, stimulated third-stage larvae and adults. The performances of the assays were compared to the motility assay using three standard drugs: albendazole, levamisole and ivermectin $(100-1 \mu \mathrm{g} / \mathrm{ml})$. None of the assays investigated offered an advantage over the motility assay, because they were all inapplicable to third-stage larvae, which were presumably metabolically and physically too inactive. Among all assays tested the xCELLigence System performed best on adult worms as the test was accurate, simple, required a minimal number of worms and offered the possibility for conducting a medium-throughput screening.

Key words: hookworm, Ancylostoma ceylanicum, in vitro assays, motility assay, feeding inhibition assay, acid phosphatase, Alamar Blue $^{\circledR}$, MTT, xCELLigence System, calorimetry.

\section{INTRODUCTION}

The hookworms, Ancylostoma duodenale and Necator americanus infect an estimated 600 million people worldwide and are major causes of global morbidity accounting for as many as $22 \cdot 1$ million disabilityadjusted life years (DALYs) lost annually (Bethony et al. 2006; Chan, 1997). Hookworm infections belong to the so-called neglected tropical diseases and occur mostly in the poorest regions of tropical and subtropical countries (Bethony et al. 2006; Hotez et al. 2008). School-age children, pregnant women and the developing foetuses are particularly at risk of suffering severe morbidities from hookworm infections (Brooker et al. 2004).

Currently, control of hookworms relies essentially on regular anthelmintic treatment, mostly in the framework of mass drug administration campaigns (Harhay et al. 2010; Hotez, 2008; Hotez and Pecoul, 2010). Despite this, only five drugs (the two benzimidazoles albendazole and mebendazole, pyrantel pamoate, levamisole and ivermectin) are recommended by the World Health Organisation (WHO),

\footnotetext{
* Corresponding author: Department of Medical Parasitology and Infection Biology, Swiss Tropical and Public Health Institute, P.O. Box, CH-4002 Basel, Switzerland. Tel.: +4161284 8218; Fax: +4161284 8105. E-mail: jennifer.keiser@unibas.ch
}

which have all been used since decades (WHO, 2011). In terms of cure rates only albendazole is highly effective against hookworms (Keiser and Utzinger, 2010). In addition, resistance to these drugs is already widely spread among livestock (Wolstenholme et al. 2004) and therefore there are concerns about the emergence of drug resistance among human helminth populations. Hence, there is a pressing need to discover and develop alternative anthelmintics (Geerts and Gryseels, 2001; Kaplan, 2004) and robust tools to monitor helminths drug susceptibility.

Today, the few ongoing drug discovery efforts on human nematodes rely on low- to mediumthroughput in vitro whole organism drug screening. In more detail, the current assay of choice, the motility assay, is based on the microscopic evaluation of the worms' viability, following drug exposure and subsequent stimulation of worms (Gill et al. 1991; Kotze et al. 2004; Satou et al. 2001). The motility assay can be performed with different developmental stages, and requires little laboratory equipment. However, it is time consuming and prone to subjectivity upon reading. The development of a novel medium- to high-throughput in vitro assay with a simple readout would therefore be a great step forward in the field of nematocidal drug discovery.

In this work, we aimed to evaluate several potential alternative in vitro assays to evaluate drug effects on 
A. ceylanicum. We assessed two viability markers, Alamar Blue $^{\circledR}$, an indicator for metabolic cell function (Räz et al. 1997) and the MTT reduction assay, which is based on a colourimetric reaction involving pyridine nucleotides cofactors (Berridge and Tan, 1993; Mosmann, 1983). In addition, we measured acid phosphatase, which is secreted in large amounts by several nematode species in feeding stages, possibly to promote extracorporeal digestion and tissue penetration (Maki and Yanagisawa, 1980; MartinezGrueiro, 2002) and which is a good indicator of the worms' fitness. We also evaluated the feeding inhibition assay (Hawdon and Schad, 1990; Kopp et al. 2008), and two fairly new technologies, namely isothermal calorimetry (Braissant et al. 2010) and the xCELLigence System (Roche Inc.) (Smout et al. 2010). We analysed the effect of albendazole, levamisole and ivermectin on L3, stimulated L3 and adults in these assays and compared findings with results obtained with the current method of choice, the motility assay. Finally, advantages and disadvantages of the individual assays are highlighted.

\section{MATERIALS AND METHODS}

\section{Drugs}

Albendazole and ivermectin were purchased from Sigma-Aldrich (Buchs, Switzerland), and levamisole-hydrochloride was obtained from Fluka (Buchs, Switzerland). Stock solutions $(5 \mathrm{mg} / \mathrm{ml})$ were prepared for all drugs in 100\% DMSO (Fluka, Buchs, Switzerland) and stored at $4{ }^{\circ} \mathrm{C}$.

\section{Animals and parasite infections}

Three-week-old male Syrian Golden hamsters were purchased from Charles River (Sulzfeld, Germany). The A. ceylanicum life cycle has been maintained at the Swiss TPH since June 2009. Briefly, hamsters were immunosuppressed $(0.5 \mathrm{mg} / \mathrm{l}$ dexamethasone (dexamethasone water-soluble, Sigma-Aldrich) in the drinking water from one day before infection onwards. They were orally infected with 150 A. ceylanicum L3, which had been assessed for viability. Animals were kept in groups of 5 in macrolon cages under environmentally-controlled conditions (temperature: $25^{\circ} \mathrm{C}$, humidity: $70 \%$, light/dark cycle 12/12 hours) and had access to water and rodent food (Rodent Blox, Eberle NAFAG, Gossau, Switzerland). The current work was approved by the local veterinary agency based on Swiss cantonal and national regulations (permission no. 2070).

\section{In vitro assays}

\section{General procedure}

L3: In 96-well plates, $30 \mathrm{~L} 3$ per well were incubated in $200 \mu \mathrm{l}$ HBSS supplemented with $25 \mu \mathrm{g} / \mathrm{ml}$ amphotericin B (Sigma-Aldrich), $10000 \mathrm{U} / \mathrm{ml}$ penicillin and $10 \mathrm{mg} / \mathrm{ml}$ streptomycin (Sigma-Aldrich) and drug dilutions ranging from 100 to $1 \mu \mathrm{g} / \mathrm{ml}$, final concentration. The plates were incubated for 72 hours at room-temperature, in dark and humid conditions.

Stimulated L3: Third-stage larvae are in "dauer" stage and do not feed or show any metabolic activity. In the feeding inhibition assay, L3 are brought into the fourth stage, where they resume feeding, and are then exposed to drugs. We used a modified protocol from Kopp and colleagues for this transformation (Kopp et al. 2008).

L 3 were pelleted $(3000 \times \mathrm{g}, 3$ minutes $)$ and cleaned in $1 \% \mathrm{HCl} 1 \mathrm{M}$ in tap water for 10 minutes at $37^{\circ} \mathrm{C}$ and then washed twice in RPMI medium (RPMI 1640 (Gibco) supplemented with 0.5\% ALBUMAX II (Gibco), 25 mM HEPES (Sigma-Aldrich), $25 \mathrm{mM}$ $\mathrm{NaHCO}_{3}$ (Sigma-Aldrich), $25 \mu \mathrm{g} / \mathrm{ml}$ amphotericin B (Sigma-Aldrich), $10000 \mathrm{U} / \mathrm{ml}$ penicillin and $10 \mathrm{mg} / \mathrm{ml}$ streptomycin (Sigma-Aldrich), 15\% v/v foetal calf serum (FCS, Gibco), and $20 \mathrm{mM}$ reduced L-glutathione (Fluka)). Thirty L3 per well were incubated in $200 \mu \mathrm{l} \mathrm{RPMI}$ medium for 24 hours at $37^{\circ} \mathrm{C}$. In a next step $100 \mu \mathrm{l}$ medium were removed and replaced with $100 \mu \mathrm{l}$ of the respective drug dilution in RPMI medium. The plates were incubated for another 72 hours at $37^{\circ} \mathrm{C}, 5 \% \mathrm{CO}_{2}$.

Adult stage: In 48-well plates, 3-4 adult worms of both sexes were incubated per well in $1 \mathrm{ml} \mathrm{HBSS}$ medium supplemented with $25 \mu \mathrm{g} / \mathrm{ml}$ amphotericin B (Sigma-Aldrich), $10000 \mathrm{U} / \mathrm{ml}$ penicillin and $10 \mathrm{mg} / \mathrm{ml}$ streptomycin (Sigma-Aldrich), $10 \% \mathrm{v} / \mathrm{v}$ FCS (Gibco), and drug dilutions (100 to $1 \mu \mathrm{g} / \mathrm{ml}$ ). The plates were incubated for 72 hours at $37^{\circ} \mathrm{C}$, $5 \% \mathrm{CO}_{2}$.

\section{Larval and adult motility assay}

Following incubation of L3 and adults with drugs as described above, larval and adult motilities were evaluated under an inverted microscope (magnification $20 \times$, Carl Zeiss, Germany), following addition of hot water $\left(\sim 80^{\circ} \mathrm{C},[100 \mu \mathrm{l}] \mathrm{L3},[500 \mu \mathrm{l}]\right.$ adult worms) and exposure to the microscope light. Larvae showing no movement after stimulation were classified as dead and the percentage survival was established for each well. The viability of adult worms was assessed using a motility scale from 2 (normal movements, worms healthy) to 0 (no movements, death) and converted into percentage viability. Motility assays were conducted at least twice in triplicate.

\section{Feeding inhibition assay}

Following incubation of stimulated L3 (as described above), $100 \mu \mathrm{l}$ medium were removed from each well 
and replaced with bovine albumin conjugated with fluorescein isothiocyanate $(1.25 \mathrm{mg} / \mathrm{ml}$, final concentration, Sigma-Aldrich) and the plate was incubated for 3 hours at $37^{\circ} \mathrm{C}$. Larvae were washed 3 times in PBS, filled in individual $1.5 \mathrm{ml}$ Eppendorf tubes and distributed again into wells. Using an inverted fluorescence microscope (Carl Zeiss, Germany, magnification $100-200 \times$, excitation: $450-490 \mathrm{~nm}$, emission: $520 \mathrm{~nm}$ ), larvae whose intestinal tract was stained by more than $50 \%$ in the length were considered fit and counted (Kopp et al. 2008). The percentage survival was calculated for each well. The motility of worms was assessed in parallel without adding hot water. The assay was conducted three times.

\section{Alamar Blue ${ }^{\circledR}$ assay}

The Alamar Blue assay was adapted from the protocol developed by Räz et al. (Räz et al. 1997). After 72 hours of incubation with drugs (as summarized above), the worms (adults, L3 and stimulated L3) were transferred into $200 \mu \mathrm{l}$ freshly supplemented HBSS medium (2 adult worms, or $30 \mathrm{~L} 3$ per well) in a 96-well plate. Ten $\mu$ l resazurin (Sigma-Aldrich, $125 \mathrm{mg} / \mathrm{l}$ ) were added to each well. The plates were then incubated at $37^{\circ} \mathrm{C}, 5 \% \mathrm{CO}_{2}$ for 5 hours (up to 24 hours for adults). The resulting absorbance was measured every hour for 5 hours (and once after 24 hours for adults) in each well (excitation: $536 \mathrm{~nm}$, emission: $588 \mathrm{~nm}$, Spectramax ${ }^{\circledR}$ Gemini XS, Molecular devices, USA). The assay was carried out at least twice.

\section{MTT reduction assay}

The MTT assay was run according to James and colleagues with slight modifications (James and Davey, 2007). Drug activity was tested using a single adult worm, or $30 \mathrm{~L} 3$ per well (in duplicate) in 96 -well plates (total volume $200 \mu \mathrm{l}$ ). After 72 hours of incubation, the worms' viability was assessed microscopically (inverted microscope, magnification $20 \times$ ) without adding hot water. One hundred $\mu$ were removed from each well and replaced with $100 \mu \mathrm{l}$ MTT (thiazolyl blue tetrazolium bromide, SigmaAldrich) solution $(2.5 \mathrm{mg} / \mathrm{ml}$ final concentration). The plates were incubated for up to 3 hours at $37^{\circ} \mathrm{C}$, $5 \% \mathrm{CO}_{2}$. The worms were washed once in sterile PBS, transferred to $50 \mu \mathrm{l}$ DMSO $100 \%$ (Fluka, Buchs, Switzerland) and allowed to de-stain for 20 minutes at $37^{\circ} \mathrm{C}$. The resulting absorbance was measured at $588 \mathrm{~nm}, \operatorname{Versamax}^{\circledR}$ (Molecular Devices, USA). The assay was performed at least two times.

\section{Acid phosphatase activity assay}

The assays were carried out as described by Martinez-Grueiro et al. (Martinez-Grueiro, 2002) with small changes in the protocol. After 72 hours of incubation, adult worms were transferred into $1 \mathrm{ml}$ supplemented HBSS medium and incubated for another 5 hours at $37^{\circ} \mathrm{C}, 5 \% \mathrm{CO}_{2}$. The motility was assessed before adding reagents, without adding hot water. The supernatant was frozen at $-20{ }^{\circ} \mathrm{C}$ or directly used for the following steps. Two times $100 \mu \mathrm{l}$ of the supernatant were removed and incubated for either 1 or 2 hours at $37^{\circ} \mathrm{C}, 5 \% \mathrm{CO}_{2}$ with $50 \mu \mathrm{l}$ fresh $\rho$-nitrophenyl phosphate (pNPP, SigmaAldrich) solution $(10 \mathrm{mM}$, in sodium acetate buffer $\mathrm{pH} 4)$. The reaction was blocked with $70 \mu \mathrm{l} \mathrm{NaOH}$ $0.3 \mathrm{M}$ and the absorbance measured at $405 \mathrm{~nm}$ $\left(\right.$ Versamax $^{\circledR}$, Molecular Devices, USA). For L3 and stimulated L3, $100 \mu$ l supernatant were removed from the drug assay plate directly and incubated for 2 hours with pNPP as described above. The assay was conducted three times.

\section{Isothermal micro- and nanocalorimetry}

Isothermal calorimetry measures quantitatively exoand endothermic heat flow of metabolic processes, and has already shown applicability using different helminth models (Braissant et al. 2010; Kirchhofer et al. 2011; Manneck et al. 2011). The endpoint used in this study was the time of death of the worms. A thermostated $\left(37^{\circ} \mathrm{C}\right) 48$-chanel microcalorimeter (TAM 48, TA Instruments, New Castle, Delaware, USA) or a 3-channel nanocalorimeter (TAM-III, TA Instruments, New Castle, Delaware, USA) were used to measure the heat flow of $A$. ceylanicum over at least 3 days. Briefly, 100, 200 or 500 L3 (microcalorimetry) or 8 adult worms (micro- and nanocalorimetry) were distributed into sterile glass ampoules containing $2.7 \mathrm{ml}$ of supplemented HBSS medium. The system was allowed to equilibrate for at least 12 hours before injection of $0.3 \mathrm{ml}$ pre-warmed drug solutions (or DMSO solutions as control conditions) and allowed to equilibrate again for around 12 hours. The heat flow was continuously recorded in each ampoule and summarized to obtain an effective sampling rate of one data point every 10 minutes. Noise amplitudes observed in heat flow curves reflect the worms' motor activity. The noise amplitude curve, following exponential decay, is based on absolute values of the amplitudes of noise obtained for 20 minutes over the entire course of the experiment. The intersection of the sample curve with the background line defines the death of worms (Kirchhofer et al. 2011; Manneck et al. 2011). The nanocalorimeter offers a greater sensitivity, in the range of $20 \mathrm{nW}$. The microcalorimetry assay was performed three times, the nanocalorimetry assay was performed once.

\section{$x$ CELLigence System}

The xCELLigence System (Roche Inc.) offers an automated real-time measurement of the cellular 
electrical impedance (Xing et al. 2005) across interdigitated micro-electrodes integrated on the bottom of the 96-well plates (E-plates). An innovative application of the system for nematode worms was recently described, monitoring motilities of Haemonchus contortus, Strongyloides ratti, Ancylostoma caninum and Schistosoma mansoni (Smout et al. 2010). Measurements were displayed in the RTCA controller software (Roche Inc.) The xCELLigence System was equilibrated either to room-temperature or to $37^{\circ} \mathrm{C}$ for 2 hours before the experiment was started. Then 100 L3 or stimulated L3 or one adult worm (in a volume of $100 \mu \mathrm{l}$ ) were added to the wells. Measurements started 10 minutes before the prewarmed drugs were added $(100 \mu \mathrm{l})$. The impedance was recorded in each well every minute for 72 hours post-incubation with drugs. The signal amplitudes (noise amplitudes) were analysed from each well. As described above, the intersection of the sample motility curve (exponential decay) with the background curve is the endpoint of the analysis and represents death of worms. The assay was performed three times.

\section{Statistical analysis}

All data were analysed and plotted in Excel (Microsoft Office 2003). The motility data were analysed with the Fisher's exact test (L3 survival), and Mann-Whitney U test (adults' viability), using StatsDirect (version 2.4.5; StatsDirect Ltd; Cheshire, UK). The correlations between the feeding inhibition assay and the acid phosphatase assay with the corresponding motility assay data were tested using the Spearman rank correlation coefficient, in StatsDirect. Microcalorimetry and xCELLigence raw data were plotted using $\mathrm{R}$ ( R 2.12.0, R Development Core Team). The exponential decay curve was defined by the equation $\mathrm{H}_{0} \mathrm{e}^{-\mu \mathrm{t}}+\mathrm{c}$, where $\mu$ represents the decay rate of noise amplitudes (motor activity), $\mathrm{H}_{0}$ is the initial starting point, $\mathrm{t}$ is time and $\mathrm{c}$ is the short term noise of the calorimeter. The repartition of death time points over the course of the experiment was assessed using the Fisher's exact test (StatsDirect).

\section{RESULTS}

\section{Larval and adult motility assay}

The activities of albendazole, levamisole and ivermectin on L3 and adult worms using the motility assay are summarised in Fig. 1. Briefly, ivermectin showed the best activity against both hookworm stages 72 hours after incubation start, with $100 \mu \mathrm{g} / \mathrm{ml}$ of the drug killing $86 \cdot 1$ and $100 \%$ of larvae and adults (both $P$-values $\leqslant 0.001$ ), respectively. Surviving larvae showed spastic movements, sometimes just at one end. Levamisole exhibited a high activity with
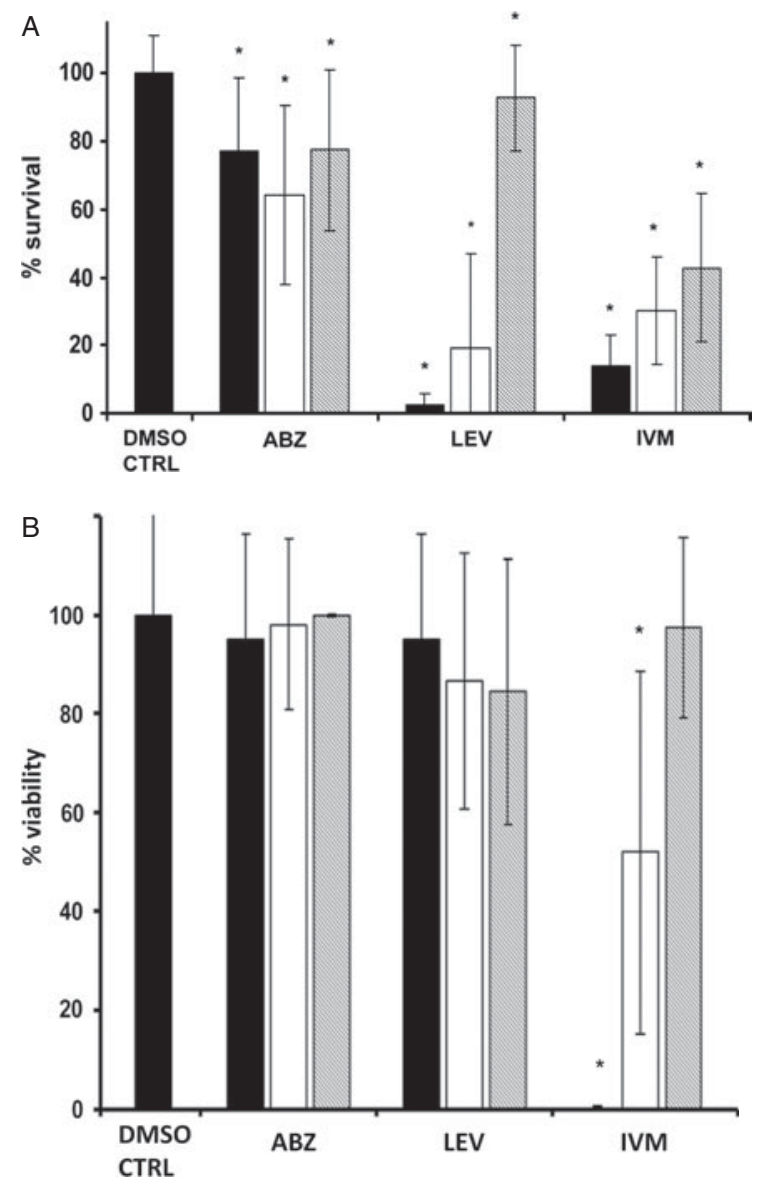

Fig 1. Anthelmintic activity of albendazole, levamisole and ivermectin against Ancylostoma ceylanicum L3 (A) and adult worms (B). The percentage survival or the viability scores are expressed as percentage of the controls. DMSO CTRL = DMSO control, $\mathrm{ABZ}=$ albendazole, $\mathrm{LEV}=$ levamisole, $\mathrm{IVM}=$ ivermectin. Black bars show $100 \mu \mathrm{g} / \mathrm{ml}$; white bars show $10 \mu \mathrm{g} / \mathrm{ml}$; striped bars show $1 \mu \mathrm{g} / \mathrm{ml}$. The assays were conducted at least twice in triplicates. ${ }^{*} \mathrm{p} \leqslant 0.05$ (A: Fisher's exact test; B: Mann-Whitney U test).

only $2 \cdot 4 \%$ of L 3 surviving following incubation with $100 \mu \mathrm{g} / \mathrm{ml}$ of the drug for 72 hours $(P<0 \cdot 001)$. On the other hand adults were nearly unaffected by levamisole (viability $>84 \%$, all $P$ values $>0 \cdot 05$ ). Albendazole displayed a moderate effect against L3 (survival of $64 \cdot 0-77 \cdot 4 \%$ at $1-100 \mu \mathrm{g} / \mathrm{ml}$, all $P$-values $<0 \cdot 001$ ), but showed no effect against adults (all $P$ values $>0 \cdot 05$ ).

\section{Feeding inhibition assay}

Levamisole and ivermectin were tested against stimulated L3 in the feeding inhibition assay (Fig. 2). On average, $84.9 \%$ of the larvae in the control wells displayed a fluorescent intestinal tract, which fulfils the criteria set by Moser et al. for a successful activation (Moser et al. 2005). Levamisoletreated parasites exhibited between $49 \cdot 0$ and $66 \cdot 0 \%$ gut staining, whereas survival was $0 \%$ at all concentrations using the motility assay (not shown). 


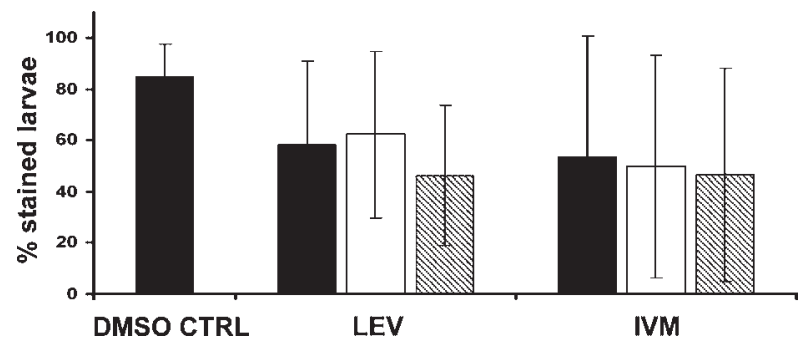

Fig. 2. Feeding inhibition assay. Percentage of stimulated L3 exhibiting fluorescent intestinal tract following treatment with levamisole or ivermectin. DMSO CTRL $=$ DMSO control, LEV = levamisole, IVM = ivermectin. Black bars show $100 \mu \mathrm{g} / \mathrm{ml}$; white bars show $10 \mu \mathrm{g} / \mathrm{ml}$; striped bars show $1 \mu \mathrm{g} / \mathrm{ml}$. Data points derive from three independent experiments.

Fluorescent guts were observed in $49 \cdot 3$ to $56 \cdot 8 \%$ of larvae following incubation with ivermectin, while $47 \cdot 3$ to $74 \cdot 4 \%$ still showed movement in the corresponding motility assay (not shown). With both treatments, no concentration-dependency and a poor reproducibility were observed. No correlation between the feeding inhibition assay and the corresponding motility data was found (Spearman rank correlation coefficient, $\rho=0 \cdot 15, P=0.233$ for positive correlation).

\section{Alamar Blue ${ }^{\circledR}$ assay}

None of the tested stages (L3, stimulated L3 and adult worms) was able to convert resazurin into resorufin within 5 hours. The medium turned slowly violet only after 5 hours. Twenty-four hours postincubation, the fluorescence intensity measured was not homogeneously distributed between wells, with emissions ranging from 3059-7427, compared to 2497 on average for the medium only.

\section{MTT reduction assay}

Following incubation of L3 and stimulated L3 with MTT, no reduction of the marker occurred and therefore neither the larvae nor the medium changed colour. Adult worms' internal tissues turned violet but their teguments remained colourless. In general, no reproducible staining pattern was observed within one treatment group (and among controls), and staining did not correspond to their capacity to move as observed with the motility assay. No reproducible absorbances could be measured at $588 \mathrm{~nm}$.

\section{Acid phosphatase activity assay}

Neither L3 nor stimulated L3 triggered a colourimetric reaction following addition of pNPP $(10 \mathrm{mM}$ solution). Adult worms produced measurable amounts of the enzymes. The absorbance measured

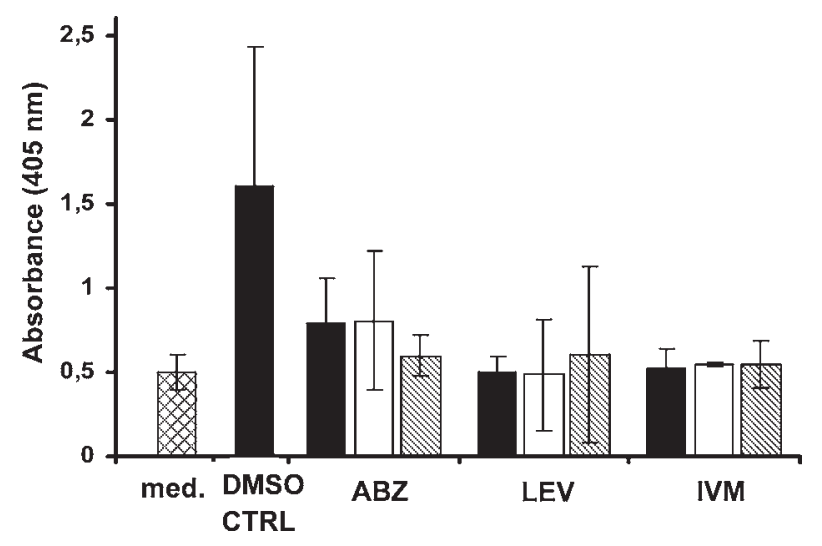

Fig. 3. Acid phosphatase activity assay for sensitivity of Ancylostoma ceylanicum adult worms to albendazole, levamisole and ivermectin. Med=medium only, DMSO CTRL $=$ DMSO control, $\mathrm{ABZ}=$ albendazole, $\mathrm{LEV}=$ levamisole, $\mathrm{IVM}=$ ivermectin. Black bars show $100 \mu \mathrm{g} / \mathrm{ml}$; white bars show $10 \mu \mathrm{g} / \mathrm{ml}$; striped bars show $1 \mu \mathrm{g} / \mathrm{ml}$. Data points derive from three independent experiments.

for control adult worms reached $1 \cdot 6$. However, the signal to noise ratio was low. The background noise produced by medium alone was high $(0 \cdot 5)$, similar to the absorbance of treated worms $(0 \cdot 48-0 \cdot 81)$. In addition, no concentration-dependency was observed (Fig. 3). Finally, no correlation (Spearman rank correlation coefficient, $\rho=0 \cdot 24, P=0 \cdot 11$ for positive correlation) was determined between the results of the acid phosphatase secretion assay and the motility of the worms (assessed before the acid phosphatase activity assay was started).

\section{Isothermal micro- and nanocalorimetry}

Microcalorimetry: Neither L3 nor stimulated L3 (up to 500 per ampoule) exhibited sufficient heat production for a stable signal. Preliminary experiments revealed that 8 worms was the minimum number of worms to measure a sufficiently large signal, in the range of $2-3 \mu \mathrm{W}$. Eight adult worms per ampoule were treated with $100 \mu \mathrm{g} / \mathrm{ml}$ levamisole, $100 \mu \mathrm{g} / \mathrm{ml}$ ivermectin, or the corresponding amount of DMSO. Mortality rates of adult worms were determined by comparing noise amplitudes in their heat flows, which derive from worm motor activities of drug-treated and control worms. The thermogenic noise of 8 dead worms was used as background noise (dotted line) and defined as $0 \cdot 13 \mu \mathrm{W}$ (not shown). Fig. 4 shows the heat flow pattern produced by control worms over 72 hours. The time-points of the death of worms are summarized in Table 1. Two control worms died between 24 and 72 hours post injection of DMSO, while 2 control worms were still alive at the end of the experiment. The noise signals were reduced to a level not different than that of dead control worms within 12 hours following addition of 


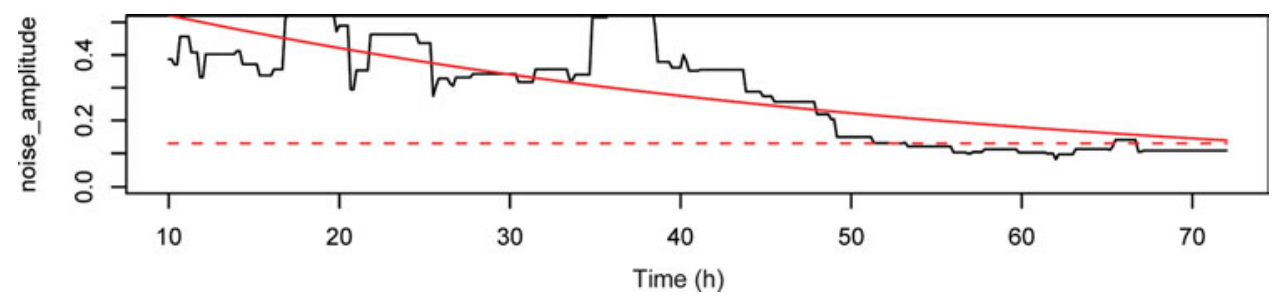

Fig. 4. Heat flow pattern of untreated adult Ancylostoma ceylanicum worms $(\mathrm{n}=8)$. The produced noise obtained for 20 minutes is averaged over 72 hours. Noise amplitude values follow exponential decay (solid line). The following equation was applied: $\mathrm{H}_{0} \mathrm{e}^{-\mu \mathrm{t}}+\mathrm{c}$, where $\mu$ represents the decay rate of noise amplitudes (motor activity), $\mathrm{H}_{0}$ is the initial starting point, $\mathrm{t}$ is time and $\mathrm{c}$ the short term noise of the microcalorimeter. The system background noise is shown as dotted line, defined as $0 \cdot 13 \mu \mathrm{W}$. The intersection of the sample curve (solid line) with the background line (dotted line) is the endpoint of worm motility and corresponds to the death of worms.

'Table 1. 'Time-points of worms' death measured by isothermal microcalorimetry, over $72 \mathrm{~h}$ after treatment with $100 \mu \mathrm{g} / \mathrm{ml}$ levamisole, ivermectin or DMSO (8 worms per ampoule)

(Death in the ampoule is defined as the intersection between the noise amplitude in the heat flow curve and the background noise line. Death was determined in 3 (ivermectin) or 4 ampoules for each treatment. The repartition of death time points is shown by the proportion and analysed using the Fisher's exact test $(* P \leqslant 0 \cdot 05)$, cumulating the time ranges.)

\begin{tabular}{llll}
\hline \hline $\begin{array}{l}\text { Time- } \\
\text { point of } \\
\text { death }\end{array}$ & $\begin{array}{l}\text { Control } \\
\text { (death/total } \\
\text { ampoules) }\end{array}$ & $\begin{array}{l}\text { Levamisole } \\
\text { (death/total } \\
\text { ampoules) }\end{array}$ & $\begin{array}{l}\text { Ivermectin } \\
\text { (death/total } \\
\text { ampoules) }\end{array}$ \\
\hline $0-12 \mathrm{~h}$ & 0 & $4 / 4^{*}$ & $3 / 3^{*}$ \\
$12-24 \mathrm{~h}$ & 0 & - & - \\
$24-48 \mathrm{~h}$ & $1 / 4$ & - & - \\
$48-72 \mathrm{~h}$ & $1 / 4$ & - & - \\
$>72 \mathrm{~h}$ & $2 / 4$ & - & - \\
\hline \hline
\end{tabular}

levamisole and ivermectin, significantly differently from the controls (both $P=0 \cdot 03$ ).

Nanocalorimetry: The absolute heat flow obtained from control worms after equilibration of the system (about 12 hours) remained in the range of $1 \cdot 5-2 \cdot 5 \mu \mathrm{W}$ during the whole experiment (Fig. 5). Heat flows recorded from levamisole- and ivermectin-treated worms were not higher than about $1 \cdot 5 \mu \mathrm{W}$, reflecting the drug effects. Signals from control and drugtreated worms remained stable over the whole experiment duration. Great noise amplitudes were observed in the control ampoule, whereas they were flattened in the treated ones, reflecting the loss of motor activities. The dead worms data were recorded in a separate experiment and no drug or medium was injected. The absolute heat flow from this ampoule was higher, in the range of $2 \cdot 5 \mu \mathrm{W}$, but stable over time and displaying minimal noise amplitudes.

\section{xCELLigence System}

Electrical impedance was measured from adults but was not detected in the $100 \mathrm{~L} 3$ nor in the stimulated

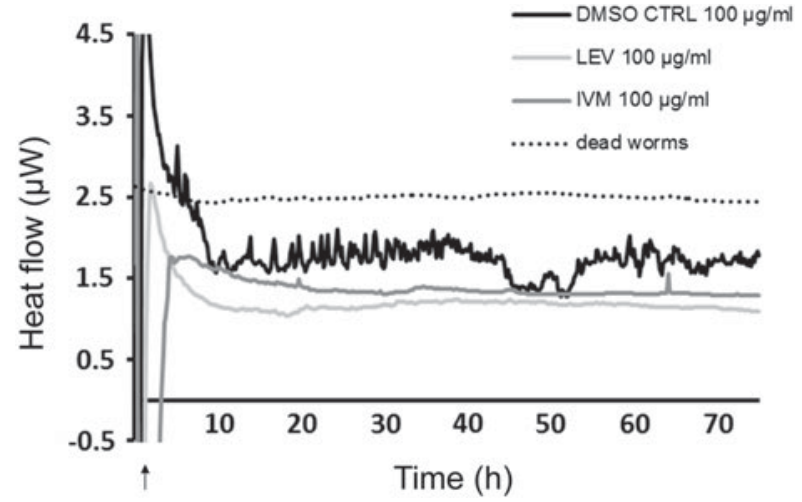

Fig. 5. Absolute heat flow of Ancylostoma ceylanicum adult worms recorded with an isothermal nanocalorimeter over 72 hours. $100 \mu \mathrm{g} / \mathrm{ml}$ levamisole, ivermectin or DMSO were injected at time $=0$, indicated by the arrow .

L3. One adult worm per well was treated with $100 \mu \mathrm{g} / \mathrm{ml}$ albendazole, $100 \mu \mathrm{g} / \mathrm{ml}$ levamisole, $100 \mu \mathrm{g} / \mathrm{ml}$ ivermectin, or the corresponding amount of DMSO. The noise produced by one dead worm was used as background noise (dotted line) and was $0 \cdot 0044$ (cell index, not shown). Out of 7 control worms analysed, 1 worm died between 24-48 hours and 2 worms died between 48-72 hours postincubation with drugs. Four worms remained alive over the entire examination period of 72 hours (Table 2). Fig. 6 shows the impedance signal curve produced by a representative control worm, still alive 72 hours after addition of DMSO. Ivermectin reduced the impedance signal to a level not different than that of dead control worms within 12 hours following addition of the drug $(P \leqslant 0 \cdot 01)$. No clear activity pattern was observed for albendazole and levamisole. Worms died at different time points following incubation with both drugs (Table 2) (both $P$-values $>0 \cdot 05$ ).

\section{DISCUSSION}

An ideal in vitro assay for drug sensitivity testing should be precise, sensitive, simple, fast and cost effective. Many in vitro assays used to study drug 
Table 2. Time-points of worms' death measured by the xCELLigence System, over $72 \mathrm{~h}$ after treatment with $100 \mu \mathrm{g} / \mathrm{ml}$ levamisole, ivermectin or DMSO (1 worm per well)

(Death in the well is defined as the intersection between the noise in the impedance curve and the background noise line. Death was determined in 3-7 wells for each treatment. The repartition of death time points is shown by the proportion and analysed using the Fisher's exact test (* $P \leqslant 0 \cdot 05)$, cumulating the time ranges.)

\begin{tabular}{lllll}
\hline \hline $\begin{array}{l}\text { Time-point } \\
\text { of death }\end{array}$ & $\begin{array}{l}\text { Control } \\
\text { (death/total } \\
\text { wells) }\end{array}$ & $\begin{array}{l}\text { Albendazole } \\
\text { (death/total } \\
\text { wells) }\end{array}$ & $\begin{array}{l}\text { Levamisole } \\
\text { (death/total } \\
\text { wells) }\end{array}$ & $\begin{array}{l}\text { Ivermectin } \\
\text { (death/total } \\
\text { wells) }\end{array}$ \\
\hline $0-12 \mathrm{~h}$ & 0 & $1 / 7$ & $2 / 3$ & $7 / 7^{*}$ \\
$12-24 \mathrm{~h}$ & 0 & $1 / 7$ & 0 & - \\
$24-48 \mathrm{~h}$ & $1 / 7$ & 0 & 0 & - \\
$48-72$ hours & $2 / 7$ & $2 / 7$ & $1 / 3$ & - \\
$>72 \mathrm{~h}$ & $4 / 7$ & $3 / 7$ & - & - \\
\hline \hline
\end{tabular}

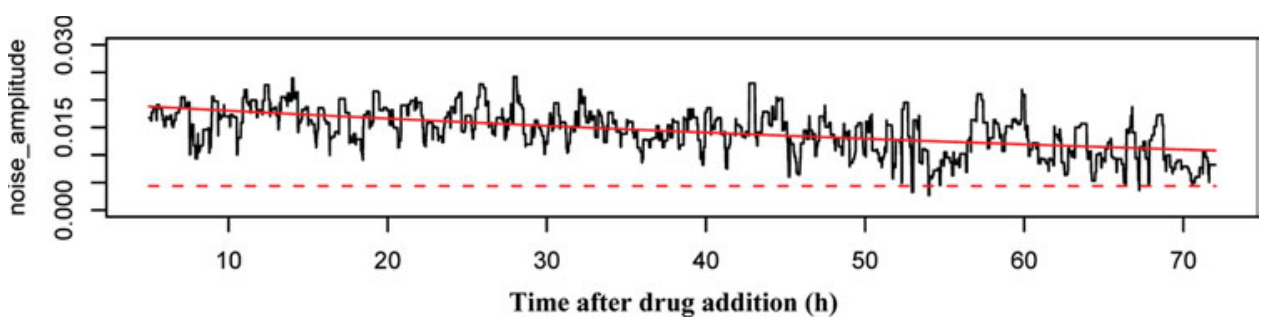

Fig. 6. Impedance pattern of adult Ancylostoma ceylanicum worms $(\mathrm{n}=1)$ measured with the xCELLigence System. The produced noise obtained for 20 minutes is averaged over 72 hours. Noise amplitude values follow exponential decay (solid line). The following equation was applied: $\mathrm{H}_{0} \mathrm{e}^{-\mu \mathrm{t}}+\mathrm{c}$, where $\mu$ represents the decay rate of noise amplitudes (motor activity), $\mathrm{H}_{0}$ is the initial starting point, $\mathrm{t}$ is time and $\mathrm{c}-$ the short term noise of the $\mathrm{xCELLigence} \mathrm{System.} \mathrm{The}$ system background noise is shown as dotted line, defined as 0.0044 (cell index). The intersection of the sample curve (solid line) with the background line (dotted line) is the endpoint of hookworm motility and corresponds to the death of worms.

effects on nematodes have drawbacks ('Taylor et al. 2002). For instance, the egg-hatch test (Le Jambre, 1976) is only suitable for the benzimidazoles, since most drugs have no effect on $A$. ceylanicum egg hatching (Tritten et al., manuscript submitted). The motility meter was found to lack sufficient sensitivity to detect drug susceptibility of bovine intestinal nematode larval stages (Demeler et al. 2010). Although cheap and simple, the motility assay is time consuming and prone to individual subjectivity. An improved drug sensitivity in vitro assay might therefore aid the development of novel hookworm drug therapies. In the present work, we studied the applicability of six alternative in vitro assays using both $A$. ceylanicum larval and adult stages, based on well-established methods and more recent technologies.

Our findings, summarized in Table 3, show that the $\mathrm{xCELLigence} \mathrm{System} \mathrm{was} \mathrm{the} \mathrm{only} \mathrm{method}$ comparing favourably to the motility assay, whereas isothermal microcalorimetry, the colourimetric assays as well as the fluorescence-based test presented no advantage over the motility assay.

None of the tested assays was suitable for stimulated or normal L3, the preferred stage for in vitro testing, since they survive for several weeks after collection, and the use of adult worms requires killing of the hamster host. Third-stage larvae are in the developmentally arrested non-feeding stage, where physiological processes are greatly reduced (Burnell et al. 2005; O’Riordan, 1989; O’Riordan, 1990), which might explain this result. Furthermore, their mouth and anus are sealed off (Cassada and Russell, 1975), limiting contacts with the environment. Several genes are differentially expressed upon feeding resumption by stimulated L3 (Moser et al. 2005), allowing a parasitic metabolic life, and adults are considered fully metabolically active (O'Riordan, 1989, 1990). However, it has been shown that the onset of development upon feeding resumption leads to more gene repressions than up-regulations (Moser et al. 2005).

The xCELLigence System offered the advantage of the format (96-well plate) and sufficiently strong signals could be obtained with only one adult worm per well. On the other hand, one hundred larvae did not yield a signal that could be detected and measured. Smout et al. showed that a large number of Haemonchus contortus or Strongyloides ratti larvae were necessary to exhibit measurable cell indices 
Table 3. Summary of the tested assays and of their performance in testing drug susceptibility against A. ceylanicum larval and adult stages

(Tests evaluated unfavourably are scored with “-”, those evaluated favourably, with a “+”.)

\begin{tabular}{|c|c|c|c|c|c|c|c|c|}
\hline \multicolumn{9}{|c|}{ Assays } \\
\hline & & Motility & $\begin{array}{l}\text { Acid } \\
\text { phosphatase }\end{array}$ & MTT & $\begin{array}{l}\text { Feeding } \\
\text { inhibition }\end{array}$ & $\begin{array}{l}\text { Alamar } \\
\text { Blue }\end{array}$ & $\begin{array}{l}\text { Micro- } \\
\text { calorimetry }\end{array}$ & $\begin{array}{l}\text { xCELLigence } \\
\text { System }\end{array}$ \\
\hline \multirow{3}{*}{ 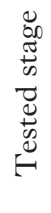 } & L3 & $\begin{array}{l}\text { Gold } \\
\text { standard }\end{array}$ & - & - & - & - & - & - \\
\hline & Stimulated L3 & $\begin{array}{l}\text { Not } \\
\text { tested }\end{array}$ & - & - & - & - & - & - \\
\hline & Adult worms & $\begin{array}{l}\text { Gold } \\
\text { Standard }\end{array}$ & - & - & - & - & - & + \\
\hline
\end{tabular}

(Smout et al. 2010), which is a great disadvantage for medium- to high-throughput assays. The cost of the $\mathrm{xCELLigence} \mathrm{apparatus} \mathrm{and} \mathrm{the} \mathrm{E-plates} \mathrm{might} \mathrm{also}$ be a drawback. In addition, untreated control worms died faster than in other in vitro assays, presumably due to incubation in a small amount of medium $(200 \mu \mathrm{l})$ for 72 hours. Hence, with the xCELLigence it is not possible to run drug assays for long periods.

It is interesting to note that according to $\mathrm{xCELLigence,} \mathrm{death} \mathrm{occurred} \mathrm{later} \mathrm{in} \mathrm{one} \mathrm{third} \mathrm{of}$ the levamisole-treated worms, compared to data from microcalorimetry. It would be necessary to investigate a larger sample size to find out whether a variation in responsiveness to levamisole exists. However, it is possible that hookworms analysed were not equally fit at the start of the assay. In both assays, the results obtained following treatment with levamisole do not correspond to the motility data.

Although isothermal microcalorimetry is generally accepted as sensitive and accurate, several limitations were noted analysing drug effects on $A$. ceylanicum. First, it was necessary to place several adult hookworms per ampoule to obtain a sufficiently strong signal, a significant disadvantage in terms of costs and ethical requirements for research involving animal hosts. Similarly to the other assays analysed, it was not possible to run the assay with larval stages. Second, the injection of the drugs triggered a perturbation of the system with great noise amplitudes being recorded for at least 8 hours and it was therefore necessary to re-equilibrate the system for several hours before drug effects on the noise amplitudes produced by the worms could be measured. For fast acting drugs it is therefore not possible to determine the exact time point of death. Our findings are in contrast to studies using isothermal microcalorimetry with the helminths Schistosoma mansoni, Fasciola hepatica or Trichuris muris, where few worms generated sufficiently stable heat flows and quickly re-equilibrated following drug injections (Kirchhofer et al. 2011; Manneck et al. 2011; Silbereisen et al. 2011). Since the same machine was used in all of these experiments, the observed insensitivity of hookworms compared to whipworms cannot be explained by equipment differences.

Increased sensitivity and signal stability was obtained using nanocalorimetry. However, the observed heat flows in control versus treated worms were very similar and the baseline signal seems to shift from an experiment to the next, as it was observed with the higher absolute heat flow of dead worms, recorded separately. It is not unlikely that microcalorimetry might record some non-biological processes contributing to the higher baseline of dead worms. Possible processes might include chemical/ enzymatic reaction initiated by the killing of the worms (performed using ethanol or freezing) or microcalorimeter baseline shift. As observed with microcalorimetry, the motor activity reflected by the noise amplitudes measured in the nanocalorimeter constituted the largest difference between control and treated conditions.

Our results obtained with the motility assay are in agreement with previous findings (Misra et al. 1981; Richards et al. 1995; Kotze et al. 2004). Briefly, albendazole had a weak effect against L3 and a moderate effect against adult worms. The low activity observed against larvae at $100 \mu \mathrm{g} / \mathrm{ml}$ albendazole might be explained by precipitation of the drug in the medium. Levamisole showed excellent efficacy at $100-10 \mu \mathrm{g} / \mathrm{ml}$ against larvae, but lacked activity against adults. Ivermectin strongly affected larvae and adult worms.

The feeding inhibition assay was first described by Hawdon and Schad (Hawdon and Schad, 1990, 1992), and proved useful in studies with $A$. caninum (Kopp et al. 2008). However, Kopp and colleagues identified lack of sufficient sensitivity with this assay, while testing resistance to pyrantel (Kopp et al. 2008). We found this assay to be time-consuming and tricky because of the numerous preparation steps, where larvae can be lost or damaged. In addition, the staining intensity of worms was weak, although the exsheathment did occur. The feeding inhibition assay therefore does not offer an advantage over the motility assay. 
Also none of the tested colourimetric assays was found to perform satisfactorily. In general, colourimetric assays are difficult to carry out with organisms as large as $A$. ceylanicum adult worms, whose size can vary, because the endpoints depend directly on the number of living cells (Mosmann, 1983; Räz et al. 1997). The Alamar Blue assay, which determines the metabolic mitochondrial biotransformation of resazurin into resorufin, was not suitable for larval stages. Furthermore, the conversion of resazurin into resorufin by adult worms was very slow (no fluorescent emission compared to medium within 5 hours), hence the applicability of the Alamar Blue assay was considered limited, in particular since this assay is highly sensitive to contaminations. We expected adult worms to reduce the dye much more quickly, as it is the case for Trichuris muris (Silbereisen et al. 2011) and therefore cannot explain this finding. It might be possible that either resazurin is not taken up sufficiently, or the mitochondrial metabolic activity is lower in $A$. ceylanicum than in other nematode species.

Upon incubation with MTT, larval stages did not detectably reduce MTT to formazan and revealed no staining. Formazan formation relies on pyridine nucleotides cofactors (Berridge and Tan, 1993), and as suggested before, larval and adult hookworm metabolisms might greatly differ. It was reported elsewhere that L3 of Caenorhabditis elegans were able to take up MTT, whereas those of $H$. contortus were not (James and Davey, 2007). In the same report, the authors suggested that the protective sheath of the L3 might prevent dye uptake, presumably occurring by diffusion. In our experiments, adults got stained, however only in an inhomogeneous and nonreproducible manner, not supporting the hypothesis of dye diffusion. It is worth mentioning that ivermectin-treated worms, paralysed if not dead, were less intensively stained than control or levamisole-treated worms. Overall, our results support the suggestion that MTT uptake occurs via pharyngeal pumping (Smith et al. 2009).

Finally, neither L3 nor stimulated L3 were able to trigger any colourimetric reaction in the acid phosphatase assay. Results from the adult acid phosphatase activity assay showed no correlation with the adult motility assay. For example, while according to the motility assay, ivermectin-treated worms were dead, the acid phosphatase production by ivermectintreated worms was still high at the highest concentration tested. It is possible, that ivermectin-treated worms might not be dead, but paralysed instead (Martin, 1997), with some metabolic activity still taking place. In addition, no concentration dependency effect was observed for ivermectin using the acid phosphatase activity assay. In contrast to our study, Martinez-Grueiro showed a clear inhibition of Heligmosomoides bakeri adult worms' acid phosphatase production following treatment with ivermectin.
In conclusion, in the present work seven test systems were examined for their usefulness in investigations of drug effects on hookworms. With exception of the motility assay, the gold standard, none of the presented assays was applicable to L3. Using adult worms, the xCELLigence System compared favourably to the motility assay. It was found convenient especially for fast-acting drugs, required a minimal amount of worms and would offer the possibility to conduct a medium-throughput screening. The results are highly accurate, since a precise endpoint can be obtained. However, additional drugs should be tested to confirm the potential advantage of the xCELLigence System over the motility assay in hookworm assays.

\section{ACKNOWLEDGEMENTS}

J. Keiser is grateful to the Swiss National Science Foundation (project no. PPOOA-114941) for financial support. We thank Dr Cornelia Hertel for giving us access to the xCELLigence System, and Frédérique Chammartin for statistical support.

\section{REFERENCES}

Berridge, M. V. and Tan, A.S. (1993). Characterization of the cellular reduction of 3-(4,5-dimethylthiazol-2-yl)-2,5-diphenyltetrazolium bromide (MTT): subcellular localization, substrate dependence, and involvement of mitochondrial electron transport in MTT reduction. Archives of Biochemistry and Biophysics 303, 474-482.

Bethony, J., Brooker, S., Albonico, M., Geiger, S. M., Loukas, A., Diemert, D. and Hotez, P. J. (2006). Soil-transmitted helminth infections: ascariasis, trichuriasis, and hookworm. Lancet 367, 1521-1532.

Braissant, O., Wirz, D., Gopfert, B. and Daniels, A. U. (2010). Use of isothermal microcalorimetry to monitor microbial activities. FEMS Microbiology Letters 303, 1-8.

Brooker, S., Bethony, J. and Hotez, P. J. (2004). Human hookworm infection in the 21st century. Advances in Parasitology 58, 197-288.

Burnell, A. M., Houthoofd, K., O'hanlon, K. and Vanfleteren, J. R. (2005). Alternate metabolism during the dauer stage of the nematode Caenorhabditis elegans. Experimental Gerontology 40, 850-856.

Cassada, R. C. and Russell, R. L. (1975). The dauer larva, a postembryonic developmental variant of the nematode Caenorhabditis elegans. Developmental Biology 46, 326-342.

Chan, M. S. (1997). The global burden of intestinal nematode infections fifty years on. Parasitology Today 13, 438-443.

Demeler, J., Kuttler, U. and Von Samson-Himmelstjerna, G. (2010). Adaptation and evaluation of three different in vitro tests for the detection of resistance to anthelmintics in gastro intestinal nematodes of cattle. Veterinary Parasitology 170, 61-70.

Geerts, S. and Gryseels, B. (2001). Anthelmintic resistance in human helminths: a review. Tropical Medicine and International Health 6, 915-921. Gill, J.H., Redwin, J. M., Van Wyk, J.A. and Lacey, E. (1991). Detection of resistance to ivermectin in Haemonchus contortus. International Fournal for Parasitology 21, 771-776.

Harhay, M. O., Horton, J. and Olliaro, P. L. (2010). Epidemiology and control of human gastrointestinal parasites in children. Expert Review of Anti-Infective Therapy 8, 219-234.

Hawdon, J. M. and Schad, G. A. (1990). Serum-stimulated feeding in vitro by third-stage infective larvae of the canine hookworm Ancylostoma caninum. Fournal of Parasitology 76, 394-398.

Hawdon, J. M. and Schad, G. A. (1992). Ancylostoma caninum: reduced glutathione stimulates feeding by third-stage infective larvae. Experimental Parasitology 75, 40-46.

Hotez, P. (2008). Hookworm and poverty. Annals of the New York Acadademy of Science 1136, 38-44.

Hotez, P. J., Brindley, P. J., Bethony, J. M., King, C. H., Pearce, E. J. and Jacobson, J. (2008). Helminth infections: the great neglected tropical diseases. Fournal of Clinical Investigation 118, 1311-1321. 
Hotez, P. J. and Pecoul, B. (2010). "Manifesto" for advancing the control and elimination of neglected tropical diseases. PLoS Neglected Tropical Diseases 4, e718.

James, C. E. and Davey, M. W. (2007). A rapid colorimetric assay for the quantitation of the viability of free-living larvae of nematodes in vitro. Parasitology Research 101, 975-980.

Kaplan, R. M. (2004). Drug resistance in nematodes of veterinary importance: a status report. Trends in Parasitology 20, 477-481.

Keiser, J. and Utzinger, J. (2010). The drugs we have and the drugs we need against major helminth infections. Advances in Parasitology 73, $197-230$

Kirchhofer, C., Vargas, M., Braissant, O., Dong, Y., Wang, X., Vennerstrom, J. L. and Keiser, J. (2011). Activity of OZ78 analogues against Fasciola hepatica and Echinostoma caproni. Acta Tropica 118, 56-62. Kopp, S. R., Coleman, G. T., Mccarthy, J. S. and Kotze, A. C. (2008). Application of in vitro anthelmintic sensitivity assays to canine parasitology: detecting resistance to pyrantel in Ancylostoma caninum. Veterinary Parasitology 152, 284-293.

Kotze, A. C., Clifford, S., O'grady, J., Behnke, J. M. and Mccarthy, J. S. (2004). An in vitro larval motility assay to determine anthelmintic sensitivity for human hookworm and Strongyloides species. American fournal of Tropical Medicine and Hygiene 71, 608-616.

Le Jambre, L. (1976). Egg hatch as an in vitro assay of thiabendazole resistance in nematodes. Veterinary Parasitology 2, 385-391.

Maki, J. and Yanagisawa, T. (1980). Acid phosphatase activity demonstrated in the nematodes, Dirofilaria immitis and Angiostrongylus cantonensis with special reference to the characters and distribution. Parasitology $\mathbf{8 0}$, 23-38.

Manneck, T., Braissant, O., Haggenmuller, Y. and Keiser, J. (2011). Isothermal microcalorimetry to study drugs against Schistosoma mansoni. Fournal of Clinical Microbiology 49, 1217-1225.

Martin, R. J. (1997). Modes of action of anthelmintic drugs. Veterinary Fournal 154 11-34.

Martinez-Grueiro, M. M. (2002). Acid phosphatase activity in excretion/ secretion products from Heligmosomoides polygyrus adults: an indicator of the physiological status of the worms. Parasitology Research 88, 946-949. Misra, A., Visen, P. K. and Katiyar, J. C. (1981). Comparative efficacy of standard antihookworm drugs against various test nematodes. Fournal of Helminthology 55, 273-278.

Moser, J. M., Freitas, T., Arasu, P. and Gibson, G. (2005). Gene expression profiles associated with the transition to parasitism in Ancylostoma caninum larvae. Molecular and Biochemical Parasitology 143, 39-48
Mosmann, T. (1983). Rapid colorimetric assay for cellular growth and survival: application to proliferation and cytotoxicity assays. Fournal of Immunological Methods 65, 55-63.

O'riordan, V. B., Burnell, A. M. (1989). Intermediary metabolism in the dauer darva of the nematode Caenorhabitis elegans-1. Glycolysis, glucogenesis, oxidative phosphorylation and the tricarboxylic acid cycle. Comparative Biochemistry and Physiology 92B, 233-238.

O'riordan, V. B., Burnell, A. M. (1990). Intermediary metabolsim in the dauer larva of the nematode Caenorhabditis elegans-II. The glyoxylate cycle and fatty-acid oxidation. Comparative Biochemistry and Physiology 95B, 125-130.

Räz, B., Iten, M., Grether-Buhler, Y., Kaminsky, R. and Brun, R. (1997). The Alamar Blue assay to determine drug sensitivity of African trypanosomes (T.b. rhodesiense and T.b. gambiense) in vitro. Acta Tropica $\mathbf{6 8}$, 139-147.

Richards, J. C., Behnke, J. M. and Duce, I. R. (1995). In vitro studies on the relative sensitivity to ivermectin of Necator americanus and Ancylostoma ceylanicum. International fournal for Parasitology 25, 1185-1191.

Satou, T., Koga, M., Koike, K., Tada, I. and Nikaido, T. (2001). Nematocidal activities of thiabendazole and ivermectin against the larvae of Strongyloides ratti and S. venezuelensis. Veterinary Parasitology 99, 311-322.

Silbereisen, A., Tritten, L. and Keiser, J. (2011). Exploration of novel in vitro assays to study drugs against Trichuris spp. Fournal of Microbiological Methods 87, 169-175.

Smith, R. A., Pontiggia, L., Waterman, C., Lichtenwalner, M. and Wasserman, J. (2009). Comparison of motility, recovery, and methylthiazolyl-tetrazolium reduction assays for use in screening plant products for anthelmintic activity. Parasitology Research 105, 1339-1343.

Smout, M. J., Kotze, A. C., Mccarthy, J. S. and Loukas, A. (2010). A novel high throughput assay for anthelmintic drug screening and resistance diagnosis by real-time monitoring of parasite motility. PLoS Neglected Tropical Diseases 4, e885.

Taylor, M. A., Hunt, K. R. and Goodyear, K. L. (2002). Anthelmintic resistance detection methods. Veterinary Parasitology 103, 183-194.

World Health Organization (2011). WHO Model List of Essential Medicines. World Health Organization, Geneva, Switzerland.

Wolstenholme, A. J., Fairweather, I., Prichard, R., Von SamsonHimmelstjerna, G. and Sangster, N. C. (2004). Drug resistance in veterinary helminths. Trends in Parasitology 20, 469-476.

Xing, J. Z., Zhu, L., Jackson, J. A., Gabos, S., Sun, X. J., Wang, X. B. and $\mathbf{X u}, \mathbf{X}$. (2005). Dynamic monitoring of cytotoxicity on microelectronic sensors. Chemical Research in Toxicology 18, 154-161. 